\title{
As bases biológicas da surdez
}

\section{The biological basis of deafness}

\section{Las bases biológicas de la sordera}

\author{
Sandro Medeiros Portella \\ ORCID: https://orcid.org/0000-0002-8823-0032 \\ Universidade Federal Fluminense, Brasil \\ E-mail: sandro_portella@hotmail.com.br \\ Luciana da Silva Goudinho \\ ORCID: https://orcid.org/0000-0003-3925-3366 \\ Universidade Federal Fluminense, Brasil \\ E-mail: goudinholuciana@gmail.com \\ Alessandra Telles Sirvinskas Ferreira \\ ORCID: https://orcid.org/0000-0002-2347-815X \\ Universidade Federal Fluminense, Brasil \\ E-mail: alessandra_ufrj@yahoo.com.br \\ Maria Cristina Barbosa Mendes \\ ORCID: https://orcid.org/0000-0001-6924-3893 \\ Universidade Federal Fluminense; Brasil \\ Mirian Renata Medeiros dos Santos Vale \\ ORCID https://orcid.org/0000-0003-0988-5872 \\ Universidade Federal Fluminense, Brasil \\ E-mail: mirianrenata06@gmail.com \\ Alessandra Furtado de Oliveira \\ ORCID: https://orcid.org/0000-0001-5696-7606 \\ Universidade Federal Fluminense, Brasil \\ E-mail: afurtadodeoliveiranovaes@yahoo.com.br \\ Elaine Alves Leite \\ ORCID: https://orcid.org/0000-0002-7020-4530 \\ Universidade Federal Fluminense, Brasil \\ E-mail: laneleite54@gmail.com \\ Elias dos Santos Silva Junior \\ ORCID: https://orcid.org/0000-0001-6972-8831 \\ Universidade Federal Fluminense, Brasil \\ E-mail: eliasjk@gmail.com \\ Michelle Joia da Silva \\ ORCID: https://orcid.org/0000-0001-6033-9290 \\ Universidade Federal Fluminense, Brasil \\ E-mail: michelejs@id.uff.br \\ Ilma Rodrigues de Souza Fausto \\ ORCID: https://orcid.org/0000-0003-3850-5066 \\ Universidade Federal de Rondônia Brasil \\ E-mail: ilma.rodrigues@ifro.edu.br \\ Sérgio Crespo Coelho da Silva Pinto \\ ORCID: https://orcid.org/0000-0001-6914-2398 \\ Universidade Federal Fluminense, Brasil \\ E-mail: screspo@id.uff.br \\ Ruth Maria Mariani Braz \\ ORCID: https://orcid.org/0000-0003-2224-9643 \\ Universidade Federal Fluminense, Brasil \\ E-mail: ruthmariani@yahoo.com.br
}

\section{Resumo}

A audição é a capacidade de perceber os sons, as vibrações periódicas de ar. A ausência da audição, no entanto, não impede a formação do desenvolvimento cognitivo do sujeito surdo, que se dá através de interações sociais, ou por imitação dos sinais de um adulto. O objetivo deste artigo é realizar uma pesquisa bibliográfica narrativa sobre as bases biológicas da surdez, mostrando as dificuldades dos surdos quanto ao acesso a saúde e a educação. Realizamos uma busca nas bases de dados científicas com as palavras chaves desta pesquisa com as palavras-chave: surdez, equidade, acessibilidade, língua brasileira de sinais e educação. Os dados analisados sugerem que a saúde precisa ser informatizada no processo de triagem auditiva neonatal, para que sejam distribuídas as ações e verbas futuras para a melhoria da qualidade de vida desta população. Estes dados só terão sentido se após a conclusão da triagem, sejam 
iniciados os processos de reabilitação auditiva e o desenvolvimento da língua de sinais. Todos os serviços de saúde e educação devem permitir o acesso à informação sobre a qualidade da saúde do paciente ou aluno surdo promovendo/possibilitando o desenvolvimento de atividades de vida diária em função da língua escolhida como meio de comunicação, seja, de sinais, orais ou português escrito.

Palavras-chave: Surdez; Equidade; Acessibilidade; Língua brasileira de sinais; Educação.

\begin{abstract}
Air vibrations and the absence of hearing does not prevent the formation of the deaf person's cognitive thinking, which occurs through social interactions, or by imitating the signs of an adult. We conducted a search in the scientific databases with the keywords of this research. In this narrative bibliographic review, research in deafness is shown, highlighting the biological bases and the difficulties of deaf Brazilians regarding access to health and education, in which theoretical materials were privileged, starting from the most recent and general ones in agreement with the theme of this research. The analyzed data suggest that health needs to be computerized in the neonatal hearing screening process, so that future actions and funds are distributed to improve the quality of life of the deaf population. These data will only make sense if, after the screening is completed, auditory rehabilitation processes and the development of sign language are initiated. All health and education services must allow access to information on the quality of health of the patient or deaf student promoting / enabling the development of activities of daily living according to the language chosen as a means of communication, be it sign or written Portuguese.
\end{abstract}

Keywords: Deafness; Equity; Accessibility; Brazilian sign language; Education.

\title{
Resumen
}

La audición es la capacidad de percibir sonidos, las vibraciones periódicas del aire. La ausencia de audición, sin embargo, no impide la formación del desarrollo cognitivo en el sujeto sordo, que tiene lugar a través de interacciones sociales o mediante la imitación de las señales de un adulto. El objetivo de este artículo es realizar una investigación bibliográfica narrativa sobre las bases biológicas de la sordera, mostrando las dificultades de las personas sordas en el acceso a la salud y la educación. Se realizó una búsqueda en bases de datos científicas con las palabras clave de esta investigación con las palabras clave: sordera, equidad, accesibilidad, lengua de signos brasileña y educación. Los datos analizados sugieren que la salud necesita ser informatizada en el proceso de cribado auditivo neonatal, para que futuras acciones y fondos se distribuyan para mejorar la calidad de vida de esta población. Estos datos solo tendrán sentido si, una vez finalizado el cribado, se inician los procesos de rehabilitación auditiva y el desarrollo de la lengua de signos. Todos los servicios de salud y educación deben permitir el acceso a información sobre la calidad de salud del paciente o estudiante sordo, promoviendo / posibilitando el desarrollo de las actividades de la vida diaria en función del idioma elegido como medio de comunicación, ya sea por señas, oral o portugués. escrito.

Palabras clave: Sordera; Equidad; Accesibilidad; Lengua de signos brasileña; Educación.

\section{Introdução}

A surdez é entendida como uma privação sensorial que interfere diretamente na comunicação, alterando a qualidade da relação do indivíduo com o meio, conforme o grau de perda apresentada em um ou nos dois ouvidos (Braz et al.,2021).

Há uma significativa diversidade de perspectivas quanto à medicina da surdez e dos surdos. Numa perspetiva histórica, encontramos o médico e matemático Girolano Cardano (1501-1576), que tendo um filho surdo, afirmou que o surdo tinha todas as condições de aprender e que o faria melhor através da escrita. No entanto, em anos posteriores, a medicina passou a se dedicar a estudos que buscassem soluções para que o deficiente auditivo pudesse oralizar, propondo aptidão para aprender qualquer conteúdo (Brazet al., 2021).

Atualmente, existem no mundo 278 milhões de pessoas com algum grau de surdez (OMS ${ }^{1}$, s/a), que se defrontam com barreiras comunicacionais e atitudinais. A Convenção das Nações Unidas sobre os direitos das pessoas com deficiência (CRPD) refere que o acesso a informação e, mais genericamente, a comunicação em saúde, é predominantemente auditivo. A Organização Mundial de saúde (OMS) considera que, em média, 5\% da população de deficientes de qualquer país tem deficiência auditiva. No Brasil os números são confusos, pois, acredita-se que sejam 9700000 pessoas com deficiências auditivas (Isaace Manfredi. 2005).

${ }^{1}$ OMS - Organização Mundial da Saúde disponível em: http:/www.who.int, acesso em 26/06/2020. 
A prática educacional inclusiva, onde temos surdos inseridos no ensino regular, exige uma pedagogia visual, adaptações de materiais e diferentes estratégias de ensino e aprendizagem para que possamos respeitar as suas singularidades linguísticas (De Carvalhoetal., 2020).

As causas mais comuns são a rubéola gestacional e outras infecções pré-natais, sendo que cerca de 33\% dos casos não têm uma causa certa. A otite média mais comum na infância é responsável por casos de deficiência auditiva leve e moderada (Isaac \& Manfredi, 2005).

Atualmente, a ação médica no atendimento a esta população de surdos esbarra na falta de comunicação na língua brasileira de sinais (Libras), acarretando assim, um distanciamento na gestão preventiva e de tratamento de suas doenças, que aflige incluindo a própria deficiência auditiva (Fellingeret al., 2012).

Estamos considerando que as pessoas com surdez são usuários da Língua de Sinais, pois, há muitos casos em que eles sequer dominam alguma forma convencional de comunicação, o que agrava ainda mais a eficiência no atendimento médico e educacional desses indivíduos. Necessitamos de um censo especificando do quantitativo de surdos que seriam usuários da Libras, para que possamos traçar ações de intervenções, seja na saúde ou na educação (Ferreira et al., 2020)

O decreto ${ }^{\circ}$ 4176, de 28 de março de 2002, do Ministério da Saúde determinou as diretrizes gerais para a assistência na saúde auditiva hospitalar no Sistema Único de Saúde (SUS). Foi gerada uma consulta pública, $\left(n^{\circ} 17\right.$ de 10 de setembro de 2013), na qual toda a sociedade civil teve a oportunidade de contribuir com sugestões e trabalhos científicos. Nestas diretrizes encontramos desde a proposta de intervenção nas gestantes até ao acompanhamento de pacientes com implante coclear (Brasil, 2014). Por isto, este é um tema de grande relevância para a sociedade, pois com o processo de inclusão dos surdos nas escolas regulares e na saúde necessitam estreitar o diálogo com o objetivo de procurarem a melhoria da qualidade de vida destes cidadãos.

A pesquisa médica acerca da surdez vem contribuindo em vários aspectos para a qualidade de vida da população surda. No entanto, cuidar dessa população não é apenas um assunto do âmbito da patologia. Por isto, neste artigo de revisão temos como objetivo identificar as principais pesquisas na área da surdez, fazendo um breve discurso da importância do conhecimento sobre as condições e limitações desta população, para o auxílio na qualificação da saúde e da educação desses indivíduos. Destacam-se ainda as bases biológicas e as dificuldades dos surdos brasileiros quanto ao acesso à saúde, com vista a melhorar as intervenções dos profissionais no atendimento a este público.

\section{Metodologia}

O trabalho foi realizado através de uma pesquisa bibliográfica narrativa qualitativa, da literatura científica, na qual se privilegiou a ligação entre os critérios de generalidade e de atualidade. Pelo critério da generalidade, começamos pelos materiais teóricos, de acordo com o tema da nossa pesquisa, utilizando as palavras chaves: equidade; acessibilidade, língua brasileira de sinais e educação; abrangendo o período de 1977 até 2021. Pelo critério da atualidade, demos prioridade às pesquisas médicas mais recentes, em revista qualificada e, por fim, artigos, resenhas, resumos, cartazes e guias contidos em sites especializados como: Pubmed, Scielo e Ministério da Saúde.Excluímos os artigos que o título e o resumo não tratavam do tema pesquisado, como por exemplo acessibilidade arquitetônica, educação infantil; educação do meio ambiente.

\section{Resultados e Discussão}

Segundo Isaac e Manfredi (2005), o sistema auditivo está formado até o quinto mês de gestação. Assim, o feto já começa a perceber os sons dos batimentos cardíacos da mãe, bem como a voz materna. O aparelho auditivo fica situado no 
osso temporal e tem como dupla função o equilíbrio e a audição. Este é o principal sentido para a aquisição da linguagem oral e é através dele que identificamos os sons da fala e do ambiente.

O aparelho auditivo está dividido em três partes: orelha externa, orelha média e orelha interna. A orelha externa é composta pelo pavilhão auricular e pelo canal auditivo. Tem a função de captar as ondas sonoras e de conduzi-las ao tímpano. O tímpano vibra e as ondas sonoras chegam então no ouvido médio. O ouvido externo serve também para auxiliar na localização da fonte sonora e protege a membrana do tímpano (Miniti et al., 2001).

A orelha média é formada pela membrana timpânica e por três ossos pequenos: martelo, bigorna e estribo, que transmitem o som até a janela oval. Esta parte da orelha tem a função de captar, transmitir, amplificar e dirigir o som para a orelha interna, e ainda de proteger a cóclea de ruídos intensos. Na orelha interna encontramos a cóclea que, em forma de caracol, é responsável pela percepção auditiva. No seu interior existe uma coluna espiral, óssea, denominada modílo bem como a rampa vestibular, o ducto coclear, a rampa timpânica, a janela oval e a janela redonda. É na orelha interna que se localizam as células ciliadas, que transformam a onda sonora em impulso elétrico para o cérebro, através da movimentação dos líquidos labirínticos (Guyton, 2006).

A audição então acontece através da captação dos sons ambientes pela orelha externa, dirigidos para a membrana timpânica. Na rampa vestibular e nos tímpanos, encontramos uma grande quantidade de potássio (perilinfa) que provoca uma vibração na membrana basilar e na cóclea. No ducto coclear há uma parte líquida chamada endolinfa (sódio). No qual se observa, durante a transmissão, a troca de íon positivo e negativo, que vai estimular as células sensoriais, aparecendo o impulso nervoso que é transmitido ao sistema nervoso central. A informação do som será conduzida através do nervo auditivo até o tronco encefálico e daí ao córtex cerebral (Guyton, 2006).

Um bloqueio nas orelhas externa e média acarreta uma redução em todas as intensidades do som, mas não causa uma perda auditiva total, pois o som pode percorrer o caminho através dos ossos do crânio, diretamente a cóclea. Se uma pessoa pode ouvir melhor pelo osso, isto mostra que provavelmente houve perda causada no caminho condutor aéreo por doenças da orelha média. Estas alterações nos mecanismos envolvidos na produção de endolinfa podem produzir perda auditiva, chamada de presbiacusia metabólica. As fibras do nervo auditivo têm seletividade dafrequência, dependente da tonotopia coclear. Issac e Manfredi, (2005), descreveu que ao pesquisar a seletividade auditiva, que quando dois sons são apresentados simultaneamente, um pode suprimir o outro. Este fenômeno é chamado de "ruído de fundo". Este ruído pode diminuir a sensibilidade e o nível das respostas a um tom, por efeitos de supressão e adaptação (Guyton, 2006).

A audição, então, é a capacidade de perceber os sons, ou seja, as vibrações de ar que somos capazes de perceber. Estas ondas sonoras são consideradas ondas de pressão, que se propagam a partir de variações de pressão do meio. Os seres humanos só conseguem ouvir ondas sonoras cujas frequências estejam compreendidas entre $20 \mathrm{~Hz}$ e $20.000 \mathrm{~Hz}$, sendo chamadas, genericamente, de sons. As ondas sonoras que possuem frequência abaixo de $20 \mathrm{~Hz}$ são denominadas infrassons e as ondas que possuem frequência superior a $20.000 \mathrm{~Hz}$ são denominados ultrassons. A intensidade ou volume dos sons é medido em unidades chamadas decibéis. A audição humana reage aos sons consideravelmente altos através do reflexo de atenuação, sons acima de 130 decibéis. Essa percepção irá depender da localização, do tom, do timbre e da intensidade da onda sonora (Isaac e Manfredi, 2005).

A surdez pode ser de diferentes tipos dependendo do grau de perda de audição. O indivíduo pode ser considerado parcialmente surdo ao apresentar uma surdez leve ou moderada. Muitas vezes pais e professores não percebem perdas auditivas leves e moderadas, no entanto, as pesquisas revelam que cerca de $6 \%$ das crianças entre quatro anos de idade e $3 \%$ das crianças com sete anos de idade apresentam algum grau de perda auditiva (Ferreira et al., 2020).

Na surdez leve há perda auditiva de até quarenta decibéis, o que impede a percepção de todos os fonemas das palavras, bem como não escuta uma voz fraca ou distante. Esse indivíduo é geralmente considerado desatento e pede para 
repetirem o que lhe falam, no entanto, essa perda não impede a aquisição da língua oral, embora possa gerar algum problema na leitura e/ou na escrita (Baelli et al., 2011)

A pessoa com surdez moderada tem perda auditiva entre quarenta e setenta decibéis; nesse grau é preciso certa intensidade na voz para que o indivíduo perceba o som de quem está falando, o que frequentemente gera atrasos de linguagem, dificuldade em compreender frases mais complexas e se apóia na percepção mais visual (Ferreira et al., 2020).

Depois do parcialmente surdo vem o que chamamos de surdo, nesse grupo estão os indivíduos com surdez severa e os com surdez profunda. As pessoas com surdez severa têm perda auditiva entre setenta e noventa decibéis; nesse grau ele percebe apenas ruídos familiares e a voz forte, a aquisição linguística oral precisará ser estimulada adequadamente através de fonoaudiólogos. As pessoas com surdez profunda têm perda auditiva superior a noventa decibéis, nesse grau não se percebe nem identifica a voz humana, o que impede a aquisição oral da língua de forma natural (Ferreira et al.,2020).

Quando nasce, esse indivíduo balbucia como qualquer outro, mas vai aos poucos reduzindo até desaparecerem quaisquer desses sons por falta de estímulos externos, que são importantíssimos para a aquisição da língua oral. Os surdos passam a utilizar de gestos e conseguirão se desenvolver através da língua de sinais, mas necessitam de modelos linguísticos. A pessoa ouvinte adquire sua língua desde que nasce ao ser estimulado pela família e pela sociedade ao seu redor, com todos falando constantemente; ao chegar à escola, já está falando e apenas precisa aprender as normas, formas e regras dessa língua. Para os surdos, o processo é completamente diferente, pois a grande maioria é filho de pais ouvintes que desconhecem a língua de sinais e, portanto, não estimulam seus filhos na aquisição desta; a escola acaba se tornando o lugar para a aquisição linguística total além do ensino formal (De Carvalho et al., 2020).

Algumas características importantes devem ser observadas nas crianças para identificar a surdez o mais cedo possível a fim de alcançar o pleno desenvolvimento destas através da promoção de um atendimento adequado. Do nascido até os três anos, observa-se que não há reação ao bater de palmas numa distância de $30 \mathrm{~cm}$; ainda não procura com os olhos de onde vem o som nem responde à fala dos pais, não atende quando chamada pelo nome, nem reage à campainha ou batidas na porta. Além desses, não entende frases simples, não imita sons e palavras simples e só reage às falas se estiver olhando para a pessoa que estiver falando. Também pode ser observado que ele usa apontar para os objetos e gestos para se comunicar, não apresentando enriquecimento vocabular oral, observa atentamente o rosto dos pais quando falam e não gosta de ouvir histórias (De Carvalho et al., 2020)

Dos três aos cinco anos, observa-se que a criança que tem perda auditiva não localiza a origem de um som nem entende ou usa palavras simples; não consegue contar oralmente algumas experiências recentes; não consegue obedecer a ordens oralmente dadas, mesmo as mais simples; a fala é difícil de entender e já começa a utilizar os gestos para as funções sociais. Com mais de cinco anos, a criança apresenta dificuldade em prestar atenção em conversas orais e não responde quando chamada oralmente apenas; confunde direções ou não as entende e normalmente dá respostas erradas às perguntas orais; não se relaciona muito bem na escola; possui vocabulário pobre em língua portuguesa; evita as pessoas, brinca sozinha; parece inquieta ou tensa.

Quanto mais precoce for à descoberta, melhor será para proporcionar os estímulos linguísticos adequados para esta criança e garantir seu desenvolvimento normal, por isso a importância da estimulação precoce. Estas crianças, quando expostas à língua de sinais, conseguem ter uma aquisição linguística adequada e passam a responder aos comandos e contar fatos recentes em Libras (língua brasileira de sinais) sem qualquer dificuldade.

O autor Pereira (2018) relatou que a estimulação precoce em crianças com surdez até os doze meses de idade e concluíram que o sistema nervoso central (SNC) apresenta plasticidade quando precocemente estimulado, permitindo o aumento de conexões nervosas; existem mudanças na estrutura do sistema nervoso em resposta a experiências vividas e com adaptações a estímulos repetidos. Com isto o cérebro amplia os seus circuitos neurais, rearranja as redes de neurônios e as 
modifica por meio das experiências. Portanto, o mapa conceitual de um adulto ou de uma pessoa surda está sujeito a constantes modificações com base no uso ou atividades de seus caminhos periféricos (Pereira, 2018), por isso a necessidade de fazer as audiometrias de acompanhamento.

Os fatores etiológicos da deficiência auditiva podem ocorrer no período pré-natal, perinatal, ou pós-natal, conforme o Quadro 1 (Isaac \& Manfredi, 2005).

Quadro 1. Resumo das causas mais comuns da perda auditiva.

\begin{tabular}{|c|c|c|}
\hline Pré-natais & Perinatais & Pós-natais \\
\hline $\begin{array}{l}\text { Baixo peso no nascimento (abaixo de } \\
\qquad 1500 \mathrm{~g})\end{array}$ & $\begin{array}{l}\text { Prematuridade, pós- } \\
\text { maturidade, anoxia }\end{array}$ & Meningite \\
\hline Ocorrência da hiper bilirrubinemia & Infecção hospitalar e outras & $\begin{array}{l}\text { Remédios ototóxicos em } \\
\text { excesso }\end{array}$ \\
\hline $\begin{array}{l}\text { Infecções congênitas como rubéola, herpes, } \\
\text { sífilis, toxoplasmose, citomegalovírus }\end{array}$ & Uso inadequado de fórceps & Sífilis adquirida \\
\hline $\begin{array}{l}\text { Uso de drogas ototóxicas, alcoolismo } \\
\text { materno, drogas (ilícitas) }\end{array}$ & $\begin{array}{l}\text { Apegar } 0 \text { a } 4 \text { no } 1^{\circ} \text { minuto ou } \\
0 \text { a } 6 \text { no } 5^{\circ} \text { minuto }\end{array}$ & $\begin{array}{l}\text { Exposição contínua a } \\
\text { ruídos ou sons muito altos. }\end{array}$ \\
\hline Pressão alta, diabetes da mãe & $\begin{array}{l}\text { Permanência em incubadora } \\
\text { por mais de } 7 \text { dias }\end{array}$ & Sarampo, Caxumba \\
\hline Exposição da mãe a radiação e outras & & $\begin{array}{l}\text { Traumatismos cranianos, } \\
\text { outros }\end{array}$ \\
\hline Anomalias craniofaciais & & \\
\hline
\end{tabular}

Fonte: Isaac e Manfredi (2005).

Neste contexto a deficiência auditiva pode ter várias causas como: a prematuridade do recém-nascido, infecções bacterianas intrauterinas, alterações endócrinas, sífilis, diabetes, drogas e medicamentos, deficiência na nutrição materna, toxemia gravídica, síndromes, infecções virais, más formações, ou ainda a origem genética, conforme ao Quadro 2.

Quadro 2. Fatores com perda progressiva. Quadro com resumo das causas da surdez relacionando ao grau da perda auditiva.

\begin{tabular}{|l|c|c|c|c|c|}
\hline Causas & Sensório & Condutiva & Mista & Bilateral & Grau \\
\hline Asfixia & + & & & + & Leve-profundo \\
\hline Meningite bacteriana & + & & & Severo-profundo \\
\hline Toxoplasmose & + & & & Moderado/profundo \\
\hline Sífilis & + & & & + & Severo/profundo \\
\hline Rubéola & + & & & + & Profundo \\
\hline Citalomegalovírus & + & & & + & Moderado/severo \\
\hline Herpes & + & & + & + & Leve/profundo \\
\hline Má formação & + & + & + & Leve/profundo \\
\hline Hiperbilirrubinemia & + & + & + & + & Leve/profundo \\
\hline História Familiar & + & & + & Moderado/profundo \\
\hline Baixo peso & + & & + & + \\
\hline
\end{tabular}

Fonte: Isaac e Manfredi (2005). 
Segundo a literatura, as questões genéticas são de maior influência em relação a surdez. Neste aspecto, a surdez congênita pode ser causada pela mutação de vários genes. Com a evolução na pesquisa do mapeamento genético, até hoje foram descobertos 57 genes não sindrômicos e mais de 1000 mutações que causam surdez. O diagnóstico da surdez congênita é feito através de exame de sangue e deve ser colhido na consulta médica, juntamente com o histórico da gestação, o exame físico e a audiometria do recém-nascido, para que seja oportunizado o atendimento precoce a estas crianças. De acordo com Isaac e Manfredi, (2005), além da desordem genética e da hereditariedade, as causas mais comuns para o risco da perda auditiva são: antecedentes familiares, disacusia sensório neural hereditária, infecções congênitas (rubéola, sífilis, herpes e toxoplasmose), anomalias craniofaciais, peso de nascimento inferior a $1500 \mathrm{~g}$, hiper bilirrubinemia, uso de medicamentos ototóxicos, meningite bacteriana, índice de Apegar 0 a 4 no primeiro minuto ou de 0 a 6 no quinto minuto, ventilação mecânica por mais de cinco dias, alcoolismo materno, uso de drogas psicotrópicas na gestação, hemorragia ventricular, convulsões neonatais e a permanência na incubadora por mais de 7 dias (Isaac \& Manfredi, 2005).

Muniz e Stroppa (2009) informam que os neonatos apresentam a associação de alguns desses indicadores de risco para a deficiência auditiva (IRDA), principalmente se permaneceram na Unidade de Terapia Intensiva (UTI) neonatal por mais de cinco dias, porque "são submetidos à ventilação mecânica prolongada e a intubação nasotraqueal, levando ao aparecimento de uma otite média secretora". Relatam que os procedimentos dos funcionários nos hospitais geram ruídos e estes estão acima do tolerável de $70 \mathrm{~dB}$ (ex: o alarme do respirador 73,3 dB); mostrou ainda que os aparelhos das unidades de tratamento intensivo (UTI) neonatal funcionam com sons graves $(250 \mathrm{~Hz})$, o que é prejudicial para o ouvido dos bebês prematuros, mais susceptível aos ruídos. A poluição sonora nas UTI deve ser controlada baixando o volume dos aparelhos, desligando os alarmes dos equipamentos e treinando a equipe de enfermagem para diminuir os ruídos. Os riscos de os recém-nascidos prematuros perderem a audição é trinta vezes maior do que nas crianças nascidas a termo.

A pesquisa realizada por Lopes e Santos (2011), realizada no município de São Paulo entre os anos de 1995 e 2005 , sugere que nos últimos 10 anos houve uma melhoria na saúde dos recém-nascidos, diminuindo o risco para a surdez. No estudo foram pontuados indicadores de prematuridade, asfixia, baixo peso, toxoplasmose, sífilis e o HIV positivo. Apesar destes indicativos, a surdez hoje atinge um número grande de brasileiros, sendo considerada asegunda maior causa da perda da qualidade da vida pela OMS (Lopes e Santos, 2011).

No ano de 1999, o comitê brasileiro sobre perdas auditivas Neonatal Universal ratificou as recomendações do Joint Commitee on infant Hearing (2007), as quais citam indicadores de risco para a deficiência auditiva (IRDA) e orientam que as crianças devem ser monitoradas quanto a audição desde os 29 dias até aos 2 anos. Mesmo que os recém-nascidos passem nos testes, é importante o acompanhamento pelo pediatra, pois existem perdas auditivas de aparecimento tardio. Assim, devem ser realizados exames complementares até aos seis meses de idade. Ao detectar a surdez, dever-se-á orientar os pais para que iniciem precocemente a intervenção educacional ou a estimulação precoce (Isaac \& Manfredi, 2005).

Após observadas essas características em qualquer das idades, deve-se procurar imediatamente um serviço de otorrinolaringologia para realizar exames como o Brainstem Evoked Response Audiometry (BERA), a fim de verificar o grau de perda auditiva sem necessidade de resposta direta da criança. $\mathrm{O}$ exame é comumente realizado com a criança dormindo, com auxílio de eletrodos e leitura cerebral, no acompanhamento das respostas aos estímulos sonoros da criança (Kyriafinis et al., 2007).

A medicina para os surdos é algo ainda pouco presente na vida desta população, visto que naperspectiva médica, a surdez deve ser tratada. A concepção clínica de muitos profissionais de saúde caracteriza a surdez como uma deficiência, a incapacidade de ouvir o som, que deve ser corrigida e tratada a fim de normalizar o surdo.

No conceito sócio/antropológico a surdez representa uma experiência visual, uma maneira diferente de observar o mundo a partir da construção de uma realidade histórica, política e social singular, não havendo determinação do 
reconhecimento de uma ou outra concepção como correta. Essa percepção da realidade por meio da experiência visual constitui a identidade surda, ambas pautadas em uma língua visuo-espacial, ou seja, na utilização de sinais (Ferreira et al.,2020).

Contudo, na defesa do saber médico para atender o sujeito surdo, encontramos diferentes perspectivas acerca desse tema. Entre elas, a perspectiva de que a surdez não é uma deficiência e sim uma diferença. Segundo De Carvalho (2020), para cuidar do surdo se faz necessário compreender a sua condição de diferente, na sua forma de comunicação e interação com o mundo, respeitando a sua singularidade linguística. Uma pessoa surda terá os mesmos problemas de saúde que qualquer ouvinte terá como uma pequena gripe, dor de garganta, etc. Conhecer a sua língua facilita a comunicação entre médico e paciente para a investigação de diagnóstico e assim estamos proporcionando uma equidade no atendimento.

Na relação médico paciente, o primeiro aspecto a se considerar é que a primeira língua utilizada pelo surdo é a língua de sinais/gestos. Deve se levar em consideração o seu aspecto peculiar de utilização de uma modalidade visual/espacial que se distingue da modalidade oral-auditiva. Entretanto, a Libras é pouco divulgada no meio acadêmico e no caso do médico, este necessita sempre de um intermediador, o intérprete, nas suas relações com o paciente.De Carvalho et al. (2020)relatou em sua pesquisa que há falta de conhecimento das mulheres surdas sobre a sua saúde, em grande parte se dá pela falta de uma comunicação comum com estes profissionais. Assim muitas delas não sabem e não entendem o significado de vários exames como o Papanicolau, mamografia, terapias de reposição hormonal.

Quando os médicos dispõem do intérprete de língua de sinais para atender pacientes surdos, estes profissionais são em número insuficiente face a demanda dos hospitais. De forma agravante, ainda se observa a ausência de sinais/gestos para os termos científicos na área médica, ou seja, a falta de glossários bilingues libras-português para os termos científicos, o que distancia ainda mais a relação médico/paciente surdo (Hintermair e Albertini, 2005).

Devido a isto alguns erros na interpretação de uma consulta podem acontecer por parte de quem está interpretando, provavelmente devido a falhas não intencionais nas traduções ou à velocidade dos movimentos das mãos, à falta de imparcialidade ou desconhecimento do conteúdo que está sendo falado pelo médico.

Recentemente Fellinger et al, (2012), relataram que o número de crianças surdas com problemas de transtornos mentais comuns é duas vezes maior do que em crianças ouvintes. Estes autores fazem um alerta para o fato de que a ausência de estimulação auditiva precoce pode levar a um atraso na linguagem, como também na memória, atenção, cognição, controle emocional, planejamento e organização de ideias. De acordo com estes autores, quando não há comunicação da família com a criança, por não haver conhecimento sobre a língua de sinais, a criança estará mais suscetível a ser afetada por distúrbios mentais em comparação aquelasestabelecem comunicação no lar.

A literatura descreve uma pesquisa com crianças surdas da Noruega em que a taxa de abuso sexual era duas vezes maior em meninas e três vezes maior nos meninos do que em crianças ouvintes. Metade das vítimas surdas relataram que foram abusadas em uma escola (tipo internato) e dos seus agressores, sendo: $44 \%$ eram ouvintes, $41 \%$ eram surdos pedófilos e 15\% sofreram abusos pelos grupos de surdos e ouvintes (Fellinger et al., 2012). Esses índices no Brasil ainda são desconhecidos, mas a capacidade de relato do abuso é comprometida pela dificuldade linguística em todos os ambientes: saúde, escolas, delegacias e demais repartições públicas.

A ausência da língua acarreta graves consequências para o desenvolvimento social, emocional e intelectual do ser humano surdo. O surdo que não for submetido a uma base linguística satisfatoriamente compartilhada e um bom nível de competência linguística para consentir uma comunicação ampla e eficaz, o mundo da criança ficará limitado a comportamentos estereotipados aprendidos em situações restritas. Assim, o pensamento humano se desenvolve através da palavra, depende das impressões sensoriais que estejam envolvidas, e assim passa a ter um significado que permite ser pensado e transmitido à outra 
pessoa. Para o surdo o significado das palavras é um fenômeno cultural intermediado que depende da existência de um sistema compartilhado de símbolos (Braz et al., 2021).

Entendemos que a comunicação é essencial para o desenvolvimento pleno do cidadão e o domínio de uma língua irá influenciar de maneira positiva nas relações de trabalho, na comunicação diária, nos registros escritos, nos meios de comunicação, na saúde do cidadão, da sua educação e no sentimento de pertencimento com o seu país (De Albuquerque et al., 2019).

A Libras é a língua da comunidade da maioria dos surdos, enquanto o português é considerado a segunda língua. Entretanto, o atendimento desta população no Sistema Único de Saúde ou nas escolas, tem sido realizado na sua segunda língua por parte dos profissionais lá presentes. O distanciamento da oportunidade de participar no planejamento, implementação e avaliação de políticas, serviços e medidas relacionados a sua vida compromete os índices de qualidade de vida desta população, índices esses ainda sem o devido conhecimento no Brasil (De Carvalho et al., 2020).

A ausência de profissionais da área de saúde e educacional com formação em Libras, intérpretes insuficientes e de forma agravante, a falta de sinais para os termos científicos da área das ciências médicas e educacional, vem contribuindo para carência no atendimento desse público tão expressivo. Essa ausência de termos priva não só a pessoa surda do acesso à informação, mas também compromete a sua saúde, a educação e o direito pleno a uma cidadania garantida por lei (De Carvalho et al., 2020).

Diversos fatores influenciam o modo como a educação deve ser oferecida aos surdos. Esta deverá ser feita, começando a observar qual o grau e tipo de perda auditiva, em que idade a surdez começou, se já havia ou não alguma aquisição linguística prévia e se houve ou há algum atendimento especializado para este indivíduo, principalmente porque quanto maior for a perda auditiva maior também será o tempo que o aluno precisará de atendimento educacional especializado para total aquisição da língua portuguesa. No entanto, em nada isso prejudicará o desenvolvimento da língua de sinais, que é acessada com maior facilidade pelo indivíduo surdo, por possuir um canal visual mais treinado e até mesmo servirá como apoio ideal para a aquisição da língua portuguesa se for devidamente estimulada tanto na escola quanto em casa, se apropriando assim da aquisição da língua e de conceitos diversos (Esteves et al., 2020).

Murdoch (2010) afirma que as áreas cerebrais que desenvolvem a língua ainda não estão definitivamente definidas. Estes estudos demonstram que o lóbulo frontal inferior esquerdo (a área da Broca) é ativado durante o processo da língua gestual, sem abranger o funcionamento do cérebro inteiro. Estes estudos concluíram que o processamento da língua é um processo complexo e é distribuído na rede neural dos dois hemisférios.

Petitto e Marentette (1991), realizaram uma pesquisa sobre como as crianças adquirem a língua e chegaram à conclusão de que não há diferença até os 14 meses de idade nos balbucios monossilábicos, entre surdos e ouvintes. Estes autores observaram que as crianças têm o mesmo tempo de maturação no seu desenvolvimento quando submetidas a um ambiente que a estimule. Contudo as vocalizações são interrompidas nos bebes surdos assim como as produções manuais são interrompidas nos bebes ouvintes, não por um déficit do aparelho fonador, mas sim devido à falta de condições propícias ao desenvolvimento da língua de sinais.

De forma interessante as crianças filhas de pais surdos, quando estimuladas nas duas línguas, crescem bilíngues, ou seja, dominam a língua na modalidade oral-auditiva e na modalidade espacial-visual. De acordo com Quadros e Pizzio (2010) o gesto inicia-se a partir dos 12 meses e as crianças surdas teriam o seu desenvolvimento na língua de sinais em período análogo à aquisição dos ouvintes. A comunicação do indivíduo surdo acontece de uma maneira não-verbal para chamar a atenção e reivindicar algo para atender as suas necessidades. Por volta de 2 a 3 anos, as crianças desenvolvem o seu vocabulário, mas como $90 \%$ dos surdos são filhos de pais ouvintes que não dominam a língua de sinais, nos surdos este processo tem acontecido mais tardiamente. 
Atualmente existem estudantes na idade de 18 a 19 anos que leem como uma criança de 8 anos, ou seja, apresentam vocabulário restrito e menos complexo. Quadros e Pizzio (2010) menciona que os níveis de interlíngua podem variar quanto ao entendimento do português escrito em três níveis. Por isto uma receita médica precisa ser traduzida, mesmo para pessoas surdas por vezes alfabetizadas, para que o paciente não tome os medicamentos incorretamente e nas escolas os conceitos precisam ser adquiridos.

Segundo Hauland e Allen (2009), a língua gestual/Sinais só foi reconhecida oficialmente em quarenta e quatro dos noventa e três países inquiridos no relatório mundial das federações de surdos, fazendo parte o Brasil que reconhece este direito.

Quando pensamos na inclusão do paciente surdo no sistema de saúde e do aluno surdo nas escolas, temos que pensar também na questão do intérprete participando desse processo, e em muitos casos a qualificação deste intermediador deve ser cuidadosa tendo em vista a sua importância na intermediação. A construção do conhecimento, incluindo para a saúde, segurança, educação e cidadania, implica captar as transformações ou reconstruções mentais que somos capazes de incorporar. Por isto, os saberes médico e educacional necessitam encontrar todas as formas factíveis e eficientes de comunicação com a comunidade surda e repensar a relação médico/paciente e professor/aluno (De Carvalho et al., 2020).

\section{Conclusão}

Todos os serviços de saúde e educacionais devem permitir que o surdo tenha acesso as informações para que ele possa gerenciar a sua vida através da língua que ele escolher como meio de comunicação, seja, de sinais ou português escrito. Para isto acontecer precisamos de ações compartilhadas de todos os profissionais de saúde e educacional, competentes nas duas línguas, oral e de sinais com formação competente para tal, assim estaremos contribuindo para que tenha qualidade de vida melhor.

Temos que oferecer a oportunidade de escolha às famílias pela oralização, ou pela língua de sinais, se possível as duas, pois são canais diferentes em que um não inviabiliza o outra.

A inclusão é um processo demorado e gradativo onde a ciência e a ideologia caminham juntas para a construção de uma verdadeira sociedade inclusiva. Assim, a criação de novos sinais na Libras para a área da saúde ou na área educacional deverá interferir na aprendizagem de novos conceitos e através da comunicação multimodal facilitar as interações entre os ouvintes e surdos. Um signo linguístico para a compreensão das Ciências deve ser representado por diferentes modos semióticos para que haja a compreensão do conceito a ser tratado pela pessoa surda em diferentes contextos.

Os dados da saúde precisam ser informatizados no processo de triagem auditiva neonatal, bem como outros aspectos médicos e sociais para que sejam distribuídas as ações e verbas futuras para a melhoria da qualidade de vida da população dos surdos. Estes dados só terão sentido se após a conclusão da triagem, forem iniciados os processos de reabilitação auditiva e o desenvolvimento da língua de sinais. O surdo não pode obter ajuda em diferentes setores da sociedade como saúde, educação, para resolver problemas enquanto as barreiras de comunicação não forem quebradas e não garantirmos o seu acesso e equidade a todas as informações de forma ampla.

\section{Referências}

Brasil (2014) Diretrizes gerais para a assistência da Saúde Auditiva Hospitalar no sistema Único de Saúde - SUS. https://bit.ly/3kRRjJm

Braz, R. M. M. et al (2021). Repensando As Práticas Pedagógicas A Partir do Letramento Visual e da Acessibilidade das Pessoas com Impedimento Auditivo. \# Tear: Revista De Educação, Ciência E Tecnologia, 10.1. https://doi.org/10.35819/tear.v10.n1.a4984

Baelli I. M. M et al. (2011) Comunidades Surdas: ¿pacientes ou cidadãos? Gaceta Sanitária, Espanha. 
Comitê Conjunto de Audição Infantil. (2007). Declaração de posicionamento do ano de 2007: princípios e diretrizes para programas de detecção e intervenção auditiva precoce. Pediatrics, 120 (4), 898-921. https://bit.ly/3iOi7Ym.

De Albuquerque Abreu, J., de Assis, L. S., de Almeida, L. D. C., Braz, R. M. M., \& Mota, V. M. T. (2019). A Linguagem científica e a Língua Brasileira de Sinais: Estratégias para a criação de sinais, in: Pesquisa no ensino de Física 2, 1-388. 10.22533/at.ed.10419280317

De Carvalho, J. N., Gomes, S. A. O., \& Braz, R. M. M. (2020). Construindo um blog educativo sobre a sexualidade para alunos com deficiência auditiva. Revista Práxis, 12(23). : https://bit.ly/3yfZdjD;

Esteves, Â. S. M., Braz, R. M. M., \& de Mello, D. (2020). As multiplicidades rizomáticas do sujeito-surdo-social-plural no processo de letramento bilíngue. Revista Educação Especial, 33, 1-20.https://doi.org/10.5902/1984686X42625

Fellinger, J., Holzinger, D., \& Pollard, R. (2012). Saúde mental de pessoas surdas. The Lancet, 379 (9820), 1037-1044. Available in:https://bit.ly/2V5OJ7y. Acesso em: 20 junho de 2021.

Ferreira, A. T. S., Braz, R. M. M., \& de Farias Melo, I. C. N. (2020). FolcloLibras: cantigas de rodaacessíveis para surdos. Conhecimento \& Diversidade, 12(26), 116-136.http://dx.doi.org/10.18316/rcd.v12i26.6780

Guyton, A. C. (2006). Tratado de fisiologia médica. Elsevier Brasil.

Hauland H., \& Allen C. (2009). Deaf people, and Human Rights. Report of the World Federation of the Deaf.

Hintermair, M., \& Albertini, J. A. (2005). Ethics, deafness, and new medical technologies. Journal of Deaf Studies and Deaf Education, 10(2), 184-192. https://doi.org/10.1093/deafed/eni018

Isaac, M. L., \& Manfredi, A. K. (2005). Diagnóstico Precoce Da Surdez Na Infância. Medicina (Ribeirão Preto), 38(3/4), 235-244. HTTPS://DOI.ORG/10.11606/ISSN.2176-7262.V38I3/4P235-244.

Kyriafinis, G., Vital, V., Psifidis, A., Constantinidis, J., Nikolaou, A., Hitoglou- Antoniadou, M., \& Kouloulas, A. (2007). Preoperative evaluation, surgical procedure, follow up and results of 150 cochlear implantations. Hippokratia, 11(2), 77.: https://bit.ly/3zAn5P9

Lopes, M. K. D., \& Santos, T. M. M. (2011). Comparação dos indicadores de risco para surdez em neonatos encontrados nos anos de 1995 e 2005. Arquivos Internacionais de Otorrinolaringologia, 15(1), 35 - 40. https://bit.ly/3kRAI8y

Miniti, A., Bento, R. F., \& Butugan. (2001), O. Otorrinolaringologia: clínica e cirúrgica (Vol. 2). Atheneu.

Muniz, L. M., \& Stroppa, M. A. (2009). Desconfortos dos pacientes internados na UTI, quanto a poluição sonora. RAHIS, 4(3), 56-62. https://doi.org/10.21450/rahis.v0i3.808

Murdoch, B. E. (2010). The cerebellum and language: historical perspective and review. Cortex, 46(7), 858-868. https://doi.org/10.1016/j.cortex.2009.07.018

Pereira, J. C. D. S. (2018). A importância da estimulação precoce no desenvolvimento da criança surda.Monografia da Graduação do curso de Licenciatura em Pedagogia BilíngueInstituto Federal de Goiás. https://bit.ly/3kLXZIS

Petitto, L. A., \& Marentette, P. F. (1991). Babbling in the manual mode: Evidence for the ontogeny of language. Science, 251(5000), 1493-1496. 10.1126/science.2006424

Quadros, R., \& Pizzio, A. (2010). Bases biológicas e aquisição de linguagem.

World Health Organization- http://www.who.int/. 